\title{
SOBREVIVÊNCIA E RENOVAÇÃO: ESOPO, FEDRO E LA FONTAINE
}

\author{
Juan Manuel Terenzi \\ Universidade Federal de Santa Catarina \\ Florianópolis, Santa Catarina, Brasil \\ Telma Scherer \\ Universidade do Estado de Santa Catarina, Centro de Artes \\ Florianópolis, Santa Catarina, Brasil
}

\begin{abstract}
Resumo: Este artigo aborda o percurso de três fábulas atribuídas a Esopo, e que foram traduzidas ao latim por Fedro e ao francês por La Fontaine. Inicialmente, efetuamos um breve percurso histórico a fim de acompanhar o nascimento desse gênero já na Antiguidade. Em seguida, nos dedicamos à análise das fábulas "A raposa e as uvas", "O cão e o pedaço de carne" e "A raposa e a máscara" nas três línguas, com o intuito de verificar possíveis continuidades e mudanças que renovam a persistência do gênero nas diversas temporalidades.
\end{abstract}

Palavras-chaves: Esopo; Fedro; La Fontaine

\section{SURVIVAL AND RENEWAL: AESOP, PHAEDRUS AND LA FONTAINE}

\begin{abstract}
This article accompanies the path of three fables credited to Aesop that were translated to Latin by Phaedrus and to French by La Fontaine. First, we make a brief historical course to accompany the birth of this genre in Antiquity. Then, we analyze all the chosen fables: "The fox and the grapes", "The dog and the shadow", "The fox and the masque" in all three languages, in order to identify possible continuities and changes that renew the persistency of this genre at different times.
\end{abstract}

Keywords: Aesop; Phaedrus; La Fontaine 
Atribui-se a Hesíodo a primeira fábula do Ocidente, inserida em Os trabalhos e os dias (202-212) ${ }^{1}$ em um momento crucial da narrativa, em que se discute sobre o papel da justiça. A palavra utilizada por Hesíodo para designar a história do rouxinol

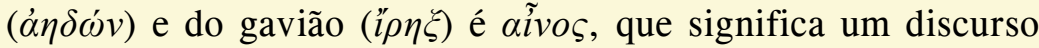
importante, conto ou provérbio. Contudo, o conjunto de fábulas que versam sobre os mais diversos animais, e inclusive árvores, são imputadas a Esopo (por volta do século VII a.C.), e ainda hoje sobrevivem no imaginário dos mais diversos povos. Se a Ilíada e a Odisseia são consideradas como frutos da atividade poética de Homero - um aedo cego que oralmente transmitia os feitos ocorridos antes, durante e após a guerra de Troia - as fábulas gregas às quais estamos aqui nos referindo, foram conferidas a Esopo, apesar de ele, provavelmente, jamais ter escrito uma só linha delas, sendo a transmissão oral o instrumento para sua longevidade.

Fontes provenientes da Grécia Antiga, como Heródoto, Aristóteles, Platão, Aristófanes e Demócrito referem-se ao seu nome, indicando-o como origem das fábulas. O primeiro, afirma no livro II de suas Histórias que ele fora escravo de um filósofo cujo nome era Xanto, proveniente de Samos. Da mesma fonte, lemos que sua morte fora violenta, tendo sido linchado pelo povo de Delfos, provavelmente em virtude de seu sarcasmo. Por seu turno, Aristóteles na Retórica relata que ele discursara na Assembleia de Samos defendendo um demagogo. Enquanto Platão, no diálogo Fédon, e Aristófanes, na comédia As aves (471), citam de passagem

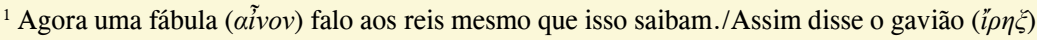

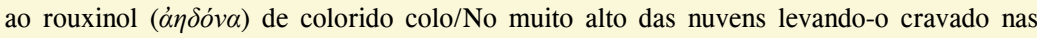
garras;/Ele miserável varado todo por recurvadas garras/Gemia enquanto o outro prepotente ia lhe dizendo:/“Desafortunado, o que gritas? Tem a ti um bem mais forte;/Tu irás por onde eu te levar, mesmo sendo bom cantor ( $\kappa \alpha \grave{~ \alpha o o l \delta o ̀ v ~ \varepsilon ́ o v ̃ ~} \sigma \alpha v)$;/Alimento, se quiser, de ti farei ou até te soltarei./Insensato $(\ddot{\alpha} \varphi \rho \omega \nu)$ quem com mais fortes queira medir-se/De vitória é privado e sofre, além de penas, vexame.

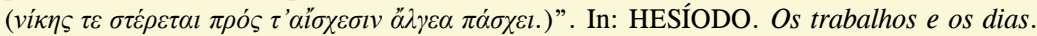
Tradução, introdução e comentários de Mary de Camargo Neves Lafer. São Paulo: Iluminuras, 2006, pp. 34, 37.
} 
seu nome ${ }^{2}$. Finalmente, Demócrito faz referência à fábula do cão que carrega entre os dentes um pedaço de carne, uma das fábulas que iremos analisar aqui. Eis o fragmento do filósofo: "El deseo

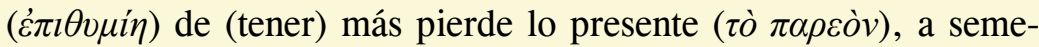
janza del perro de Esopo."3

Todas estas referências fazem com que o nome de Esopo ganhe força e identifique o papel desempenhado pelo conjunto de suas fábulas, estando vinculadas, sobretudo, com a paideia grega, da mesma maneira que os versos homéricos. Ao longo dos anos, as fábulas foram sendo associadas com seu aspecto moral apenas. Figura tão incerta como a grande maioria proveniente de tempos

${ }^{2}$ Em relação a Heródoto, podemos ler nas últimas frases do capítulo 134 do livro II que

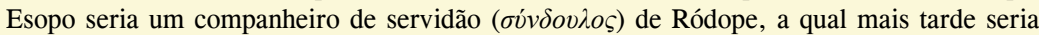
comprada por Xanto para ir servir no Egito, embora rapidamente fosse libertada pelo irmão da poeta Safo (cf. Heródoto, livro II, cap. 135). Heródoto refere também que ele

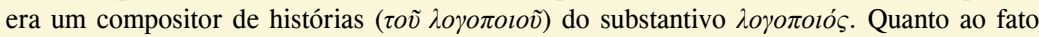
de Esopo ter tido uma morte violenta em Delfos, lemos no desfecho do capítulo 134 que

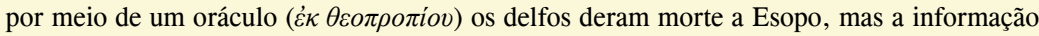
é sucinta e nada mais acrescenta-se a respeito deste fato terrível. Em Platão, a menção ao fabulista é rápida também. Logo no início do diálogo Fédon (60c-61b), ao discorrer sobre o prazer $(\dot{\eta} \delta \dot{v} \varsigma)$ e a dor $(\lambda v \pi \eta \rho o ́ \varsigma)$, Sócrates afirma que tal debate seria caro a Esopo, e este teria criado uma fábula $(\mu \tilde{v} \theta o v)$. Poucas linhas adiante, Cebes interrompe Sócrates dizendo que este transpusera para o metro cantado os contos ( $\lambda \dot{o} \gamma o \varsigma)$ de Esopo. Importante destacar aqui a palavra lógos, a qual muitas vezes, alternando com mythos, está marcada no epílogo das fábulas. A última aparição do nome de Esopo neste diálogo é uma passagem

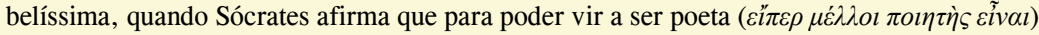
não basta que ele saiba escrever em versos, mas também ser apto a inventar ficções

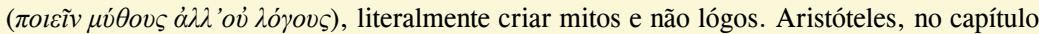
20 do livro II da Retórica, utiliza a palavra lógos para designar as fábulas escritas por Esopo

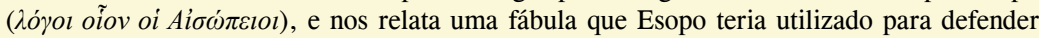

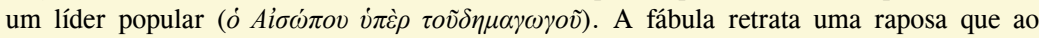
atravessar um rio fica presa num buraco rochoso, e com o tempo fica infestada de pulgas. Um ouriço, vendo a situação desagradável da raposa, decide ajudá-la, oferecendo-se para retirar as pulgas. A raposa nega a ajuda, afirmando que aquelas pulgas já estão fartas dela, e se as retirasse, novas pulgas viriam sugar-lhe o sangue. Aristófanes, na comédia As aves, menciona o nome de Esopo em duas ocasiões (471 e 651), na primeira delas chamando seu interlocutor de ignorante $(\dot{\alpha} \mu \alpha \theta \grave{\eta} \varsigma)$ por não conhecer a fábula de Esopo sobre a cotovia ( $\kappa \rho \nu \delta o ́ \varsigma)$, e na segunda para chamar a atenção entre a aliança que a raposa trava com a águia,

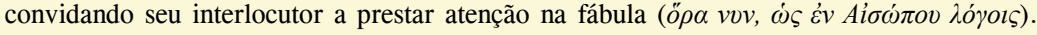
Novamente, vemos aqui a palavra lógos.

${ }^{3}$ FILÓSOFOS PRESOCRÁTICOS. Fragmentos II. Traducción de Ramón Cornavaca. Buenos Aires: Losada, 2009, p. 461. 
remotos, Esopo é identificado diretamente com as fábulas, restando praticamente nula qualquer informação sobre sua vida pessoal, como lemos nesta passagem escrita por Chambry na introdução à sua tradução:

\begin{abstract}
On sait que chez les Grecs tout genre littéraire devait avoir un inventeur, un $\varepsilon \dot{v} \rho \varepsilon \tau \eta \dot{s}$. Il en fallait un à la fable comme aux autres genres: à défaut d'un inventeur authentique, n'en a-t-on pas imaginé un faux? En tout cas, il s'est rencontré plus d'un savant pour soutenir qu'Ésope était un nom sans realité, destine à server de patron à la fable. ${ }^{4}$
\end{abstract}

Porém, o que procuramos destacar neste artigo é como estas fábulas foram se modificando e sendo traduzidas para outras línguas. Interessa-nos, principalmente, a passagem, ou recontextualização destas fábulas, para o universo latino - através de Fedro, e para o universo francês do século XVII - com La Fontaine, o qual ainda lhe rende uma bela homenagem ao escrever uma biografia sobre sua pessoa.

Existe a hipótese de que o próprio nome de Esopo seria originário da palavra "etíope", utilizada pelos gregos para designar qualquer indivíduo proveniente da África. A controvérsia em torno de Esopo e de sua proveniência não será discutida aqui, apesar do interesse que suscita - considerando-se que muitos dos animais que aparecem nas suas fábulas eram desconhecidos no continente europeu.

As fábulas de Esopo que estaremos utilizando, estimadas em um total de 358, são aquelas que foram recolhidas em uma edição crítica a cargo de Émile Chambry, e que se concentram em um núcleo central ao qual foram sendo acrescentadas outras de diversas origens. As fábulas vertidas ao latim por Fedro serão retiradas da edição de Lucian Müller Phaedri Fabulae Aesopi (Fábulas Esópicas de Fedro). Interessante notar, portanto, que estas fábulas

${ }^{4}$ ÉSOPE (Texte établi et traduit par Émile Chambry, 1927). Fables. Paris: Les Belles Lettres, 1967, p.ix.

Cad. Trad., Florianópolis, v. 38, $\mathrm{n}^{0}$ 2, p. 97-119, mai-ago, 2018 
latinas são devedoras diretas da fonte grega, como fica explícito já a partir do título. Todavia, Fedro inventa novas fábulas, incorporando inclusive Esopo como personagem em algumas delas ${ }^{5}$. E mais de dois mil anos depois, veremos ainda como La Fontaine lidou com a temática das fábulas, incrementando-as no que tange ao seu "recheio", denominado tecnicamente de corpo central, apesar de também ser devedor direto das fábulas atribuídas a Esopo. Há uma mudança em relação ao aspecto moral em La Fontaine: "Em suma, com La Fontaine a retórica poetiza-se, abandonando o seu estatuto oratório e forense para se transformar numa arte das figuras e ornamentos, onde a forma desempenha um papel determinante, relegando o conteúdo moral para segundo plano [...]" ${ }^{6}$. No entanto, a composição básica de uma fábula - prólogo, corpo central e epílogo de teor moral - mantém-se praticamente intacta ao longo destes três autores.

Decidiu-se escolher três fábulas que obrigatoriamente estivessem presentes nas três línguas aqui abordadas - grego, latim e francês -, com a finalidade de observar mudanças tanto no aspecto lexical, quanto na estrutura sintática, como ficará claro ao vermos as rimas e o conteúdo linguístico mais enriquecido presente nas fábulas de La Fontaine.

Para começar, não poderíamos deixar de mencionar a famosa fábula da raposa e das uvas. Vejamos, então, como ela se apresenta em sua versão grega, lembrando que o texto estabelecido seguirá sempre a edição de Chambry mencionada anteriormente:

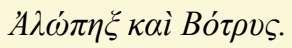

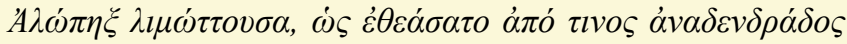

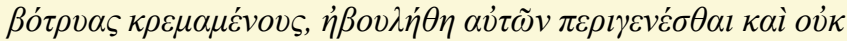

\footnotetext{
${ }^{5}$ Conforme a edição de Chambry, podemos ver que o próprio Esopo também se coloca como personagem em pelo menos uma das suas fábulas: "Esopo no estaleiro".

${ }^{6}$ NEVES, Márcia Seabra. "Fábulas na ágora: De Aristóteles ao século das Luzes". Matraga. Rio de Janeiro, v. 20, n³3 jul./dez. 2013, p. 149.
} 


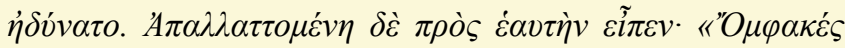

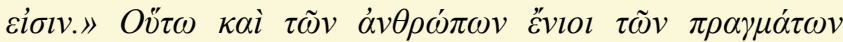

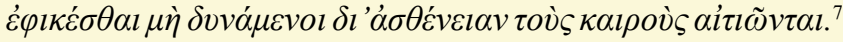

A primeira palavra da fábula é exatamente o substantivo feminino raposa $(A \lambda \omega ́ \pi \eta \xi)$, seguida de seu estado físico no momento em que se desenrola a fábula. Ela está esfomeada, como bem nos mostra o particípio presente do verbo $\lambda \iota \mu \omega ́ \tau \tau \omega$ (padecer fome) e se dirige, após vê-la ( $\dot{\varsigma} \dot{\varepsilon} \theta \varepsilon \alpha \dot{\sigma} \sigma \alpha \tau o)$, a uma vinha contendo uvas dependuradas

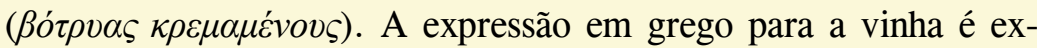
pressa pela preposição $\alpha \pi o ́$ seguida do genitivo $\tau \imath v o \varsigma \alpha \dot{\alpha} \alpha \delta \varepsilon v \delta \rho \alpha \dot{\alpha} \delta \varsigma$, sendo que o substantivo $\alpha \dot{v} \alpha \delta \varepsilon v \delta \rho \alpha ́ \varsigma$ poderia ser traduzido por vitis arbustiva ${ }^{8}$ em latim, mas como veremos, Fedro reordenará para encaixar em seus versos senários com a expressão in vinea. Seguindo a leitura da fábula, podemos testemunhar que a raposa decide colher

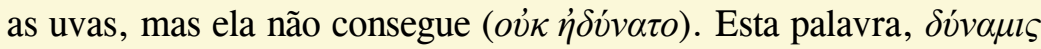
é presente também na filosofia aristótelica, na famosa oposição ato

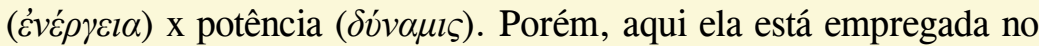
sentido mais simples de que a raposa não possuía condições físicas - poder, força - suficientes para recolher as uvas que tanto lhe apeteciam. Logo em seguida, a raposa efetua um movimento de retirada ( $А \pi \alpha \lambda \lambda \alpha \tau \tau o \mu \varepsilon \dot{v} v \eta$ ), mostrando toda sua frustração em não poder obter o alimento que satisfaria sua fome. Interessante notar que a palavra que sinaliza o movimento de retirada contém em sua construção a preposição $\dot{\alpha} \pi$, a mesma que estava presente quando a raposa se aproximara das uvas. Por fim, desdenhando sua impotência, ela afir-

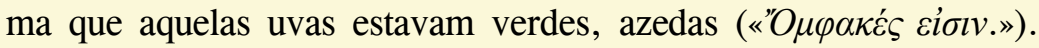
A frase que fecha a fábula - o epílogo - procura dar um aspecto moral para a atitude da raposa, generalizando-a para aqueles homens

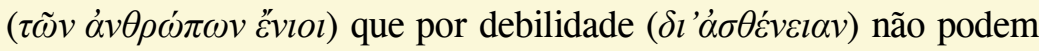

7 ÉSOPE (Texte établi et traduit par Émile Chambry, 1927). Fables. Paris: Les Belles Lettres, 1967, pp. 17, 18.

8 Informação retirada do dicionário BAILLY, A. Dictionnaire Grec-Français. Paris: Librairie Hachette, 1950, p.120. 


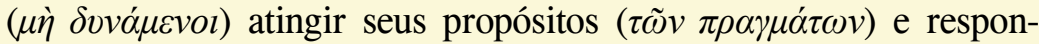

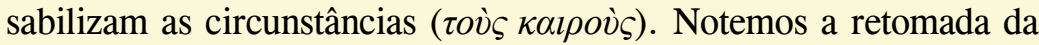
palavra $\delta v ́ v \propto \mu \iota \varsigma$ ao final da fábula, relacionando esta impotência com a debilidade de certos homens. Haveria, portanto, uma relação de causa-efeito entre $\dot{\alpha} \sigma \theta \varepsilon \dot{\varepsilon} \varepsilon \imath \alpha v$ e $\delta \dot{v} v \alpha \mu \iota$, em que a debilidade geraria a falta de potência. Em linhas gerais, Esopo buscaria utilizar uma linguagem não muito rebuscada, contendo uma mensagem que seria quase imediata para o leitor.

Na tradução ao latim, Fedro adverte aos seus leitores que ele adotara uma métrica distinta - visto que Esopo sequer escrevera em versos -, a dos versos senários (de seis pés) jâmbicos:

Aesopus auctor quam materiam repperit, Hanc ego polivi versibus senariis.

Duplex libelli dos est: quod risum movet, Et quod prudenti vitam consilio monet.

Calumniari si quis autem voluerit, Quod arbores loquantur, non tantum ferae, Fictis iocari nos meminerit fabulis. ${ }^{9}$

Com isto, ele contribui para que a fábula se afirme ainda mais como gênero: "Puis la fable se fait sa place à part avec Phèdre qui met en vers sénaires les fables d'Ésope." ${ }^{10}$ Como podemos ler na passagem que segue, este tipo de metrificação já se encontra difundido em Roma, principalmente no teatro latino arcaico: "El senario

\footnotetext{
${ }^{9}$ PHAEDRUS. Fabulae Aesopiae. L. Mueller. Leipzig. B. G. Teubner. 1876. Disponível em: http://www.perseus.tufts.edu/hopper/text?doc=Perseus \%3Atext\%3A1999.02.0118. Acesso em 07/08/2016.

Na tradução de Nicolau Firmino: "Eu poli em versos senários esta matéria que o autor (= primeiro) Esopo inventou. A vantagem do livrinho é dupla, (por)que move o riso (= faz rir) e porque adverte (= dirige) a vida por um conselho prudente (= assisado). Se alguém, porém, quiser censurar (por) que falem (até) as árvores, (e) não somente os animais, lembre-se de que nós (nos) divertimos com narrativas fingidas (= apólogos)." In: FEDRO. Tradução literal das fábulas de Fedro. Tradução de Nicolau Firmino. São Paulo: Lusitânia, 1941, p. 1.

${ }^{10}$ ÉSOPE (Texte établi et traduit par Émile Chambry, 1927). Fables. Paris: Les Belles Lettres, 1967, p.xxxi.
} 
yámbico está presente en Roma mucho antes que el trímetro; es sobre todo el verso del teatro latino arcaico (tanto comedia como tragedia) [...]. En época clásica es el verso de las fábulas de Fedro. Después de Fedro, el senario prácticamente desaparece [...]." 11

Por sua vez, o estudioso do latim Napoleão Mendes de Almeida, em sua Gramática Latina, explica de maneira sucinta - porém, clara - a caracterização do que viria a ser o verso jâmbico que encontramos na época clássica tanto em Fedro, quanto em Sêneca:

\begin{abstract}
O mais usado dos versos jâmbicos é o jâmbico senário, que exige o jambo [uma sílaba breve seguida de uma longa, ex.: virōs] somente no $6^{\circ}$ pé; os outros pés podem ser dáctilos (longa, breve, breve), espondeus (longa, longa), anapestos (breve, breve, longa), tríbracos (breve, breve, breve) e, em Fedro e em Sêneca, proceleusmáticos (breve, breve, breve, breve); a cesura se dá no meio do $2^{\circ}$, do $3^{\circ}$ ou do $4^{\circ}$ pé. ${ }^{12}$
\end{abstract}

Feita esta introdução, vejamos como lemos em latim a fábula da raposa e das uvas:

De vulpe et uva

Fame coacta vulpes alta in vinea Uvam appetebat summis saliens viribus; Quam tangere ut non potuit, discedens ait: "Nondum matura est; nolo acerbam sumere." Qui facere quae non possunt, verbis elevant, Adscribere hoc debebunt exemplum sibi. ${ }^{13}$

${ }^{11}$ CECCARELLI, Lucio. Prosodia y métrica del Latín Clásico. Con una introducción a la métrica griega. Traducción de Rocío Carande. Sevilla: Universidad de Sevilla, 1999, p. 66. ${ }^{12}$ ALMEIDA, Napoleão Mendes de. Gramática Latina: curso único e completo. São Paulo: Saraiva, 2011, p. 430.

${ }^{13}$ PHAEDRUS. Fabulae Aesopiae. L. Mueller. Leipzig. B. G. Teubner. 1876. Disponível em: http://www.perseus.tufts.edu/hopper/text?doc $=$ Perseus \%3Atext\%3A1999.02.0118\% 3Abook\%3D4\%3Apoem\%3D3. Acesso em: 07/08/2016.

Cad. Trad., Florianópolis, v. 38, no 2, p. 97-119, mai-ago, 2018 
Curiosamente, a fábula vertida ao latim possui igualmente 36 palavras - se considerarmos a contração $\delta \imath \alpha+\dot{\alpha} \sigma \theta \dot{\varepsilon} v \varepsilon \imath \alpha v=\delta \imath^{\prime} \dot{\alpha}-$

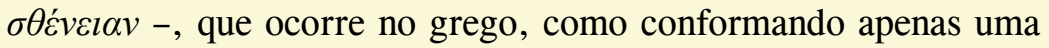
palavra. Fedro opta por posicionar em primeiro plano a condição famélica da raposa, a qual estava "coagida pela fome" (fame coacta) e já antecipa o lugar em que as uvas se encontram (alta in vinea). A raposa, com todas as suas forças, ou melhor, com as máximas forças (summis viribus) saltava (saliens, literalmente "saltando" ou "que saltava") a fim de obter as uvas apetitosas (uvam appetebat). No latim utiliza-se o acusativo singular, pois o substantivo $u v a,-a e$ também se refere à videira.

Podemos perceber que em Fedro aparece com mais clareza o esforço empreendido pela raposa através do emprego do verbo salio,-ire (saltar) no particípio presente, aqui podendo ser traduzido para o gerúndio "saltando". A fábula segue tal como no grego, ela intenta agarrar as uvas (tangere), não consegue (non potuit) - o grego também enfatizava a condição impotente da mesma (ov̉ $\kappa \dot{\eta} \delta \dot{v}$ $v \alpha \tau o$ ), como havíamos dito anteriormente - e se retira (discedens). No entanto, a fala da raposa em latim é mais eloquente, visto que ela utiliza duas palavras para descrever a "falsa" condição das uvas (nondum matura est e acerbam). Como, devido a sua impotência, não as consegue colher (sumere), a raposa afirma que as uvas ainda não se encontram maduras, e que por esse motivo ela não as deseja comer. Os últimos dois versos estão dedicados ao conteúdo moral da fábula, quando se afirma que ela (hoc exemplum) deve (debebunt, aqui o futuro simples pode ser traduzido no presente devem) ser tida como exemplo para aqueles (qui) que desprezam com palavras (verbis elevant) o que não estão aptos a conseguir (facere quae non possunt). Ou seja, o caráter reflexivo da moral (adscribere ... sibi) para os próprios "impotentes" deveria ser tida em consideração como um exercício.

Analisando agora a passagem desta fábula para os versos de La Fontaine, confirmaremos aquilo que destacávamos acima, de que a "retórica poetiza-se", isto é, a ars predomina sobre a utilitas. Se em Fedro já há um trabalho maior com a sintaxe, na verdade 
vimos que se trata de uma intenção dupla: mover ao riso (quod risum movet) e adverte a vida com um conselho prudente (quod prudenti vitam consilio monet), veremos que La Fontaine pule ainda mais a língua, e nas suas palavras, procura dar um tom mais alegre (gaieté) e teatral às fábulas, tornando-as, por assim dizer, novas. Trata-se da fábula mais curta que o francês escreveu:

\section{Le renard et les raisins}

Certain Renard gascon, d'autres disent normand, Mourant presque de faim, vit au haut d'une treille

Des raisins mûrs apparemment,

Et couverts d'une peau vermeille.

Le Galand en eut fait volontiers un repas;

Mais comme il n'y pouvait point atteindre:

Ils sont trop verts, dit-il, et bons pour des goujats.

Fit-il pas mieux que de se plaindre? ${ }^{14}$

Percebe-se, desde o primeiro verso, que a raposa grega $(\dot{\alpha} \lambda \dot{\omega} \pi \eta \xi)$ ou latina (vulpes) adquire novas qualidades, com tonalidades autóctones marcadas. É uma raposa proveniente da região da Gascônia (Certain Renard gascon) - sudoeste da França, fronteira com o país basco na Espanha -, porém, dizem (d'autres disent) que ela é da Normandia (normand) - localizada no noroeste. Os dois versos que seguem são muito próximos dos que já lemos em grego e latim, pois a raposa vê certas uvas (des raisins) que parecem maduras (mûrs), enfatizando sua condição madura no quarto verso ao ser dito que elas estão cobertas de uma casca vermelha (peau vermeille). Mais um epíteto é conferido à raposa, chamada de galante (Galand), e o verbo em francês empregado aqui para mostrar a impotência da raposa em capturar aquelas uvas é muito próximo ao usado em latim, pouvoir. Ela não consegue alcançar

$\overline{{ }^{14} \text { LA FONTAINE, Jean de. Fables. Paris: Flammarion, }}$ 1995, p. 32. 
as uvas (il n'y pouvait point atteindre), e diz que elas estão muito verdes (trop verts). No entanto, a raposa não se contenta em dizer que elas estão verdes, como as raposas de Esopo e Fedro, visto que ela acrescenta uma colocação que hoje soaria preconceituosa: elas são boas para os cabos ( goujats $^{15}$ ) - no âmbito militar - que teriam um paladar grosseiro. E finaliza interrogando ao leitor se a sua atitude não tinha sido melhor (Fit-il pas mieux) do que simplesmente lamentar-se (se plaindre). Os versos seguem um esquema de rimas $\mathrm{ABAB} / \mathrm{CDCD}$, ornamentando o conteúdo moral da fábula com uma linguagem rica em sonoridade.

A próxima fábula que vamos analisar é aquela que Demócrito inserira entre seus escritos morais - no fragmento citado anteriormente - sobre o cão que carrega um pedaço carne:

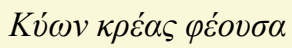

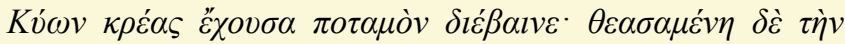

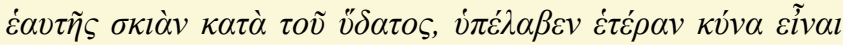

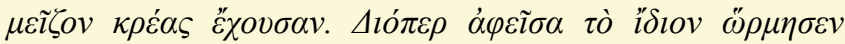

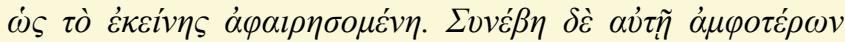

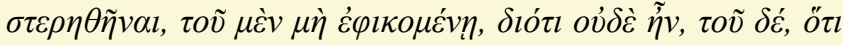

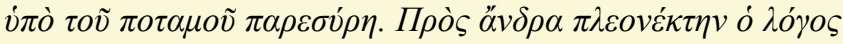

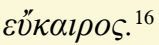

A fábula inicia com uma cadela ${ }^{17}(\kappa v ́ \omega v)$ que atravessava um

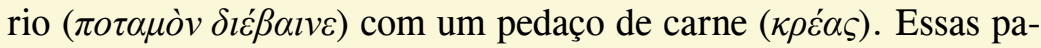
lavras estão em íntimo contato, uma seguida da outra - cadela e carne. Ao ver seu reflexo ( $\sigma \kappa \imath \grave{\alpha} v)$ na água, pensou que outra cadela

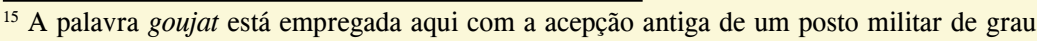
menos elevado - .valet militaire.

${ }^{16}$ ÉSOPE (Texte établi et traduit par Émile Chambry, 1927). Fables. Paris: Les Belles Lettres, 1967, p. 81.

${ }^{17}$ Inicialmente o sexo do animal permanece ambíguo, e este só será resolvido quando ler-

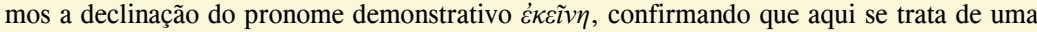
cadela.
} 


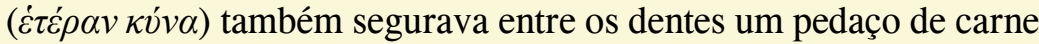
ainda maior ( $\mu \varepsilon \tilde{\imath} \zeta o v$, comparativo do adjetivo $\mu \dot{\varepsilon} \gamma \alpha \varsigma)$. Este é um momento capital da fábula, pois é possível que o pedaço realmente parecesse maior com a água. Tal descrição não aparecerá na versão latina de Fedro. Por esse motivo, a cadela decide obter o pedaço de

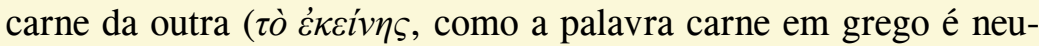
tra, aqui ela aparece representada pelo artigo neutro $\tau \grave{o}$, enquanto a cadela está representada no pronome demonstrativo declinado no

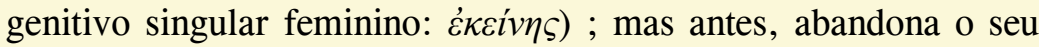

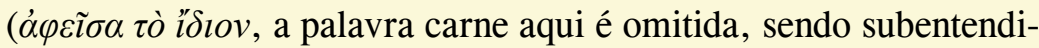
da pela palavra próprio - ¡ $\delta ı o v)$. A tensão criada entre o próprio e

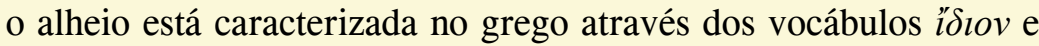

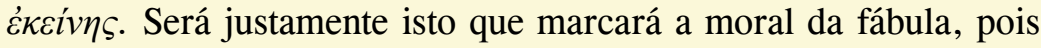
a sua ambição ou avidez lhe tirará ( $\alpha$ viñ ... $\sigma \tau \varepsilon \rho \eta \theta \tilde{\eta} v \alpha l)$ ambos os pedaços de carne ( $\dot{\alpha} \mu \varphi \circ \tau \dot{\varepsilon} \rho \omega v)$. Um deles pela sua inexistência (ov̉dè $\tilde{\eta} v$, literalmente "não era/existia/havia"), e outro fora levado pelo rio (i்ì $о \tilde{v} \pi о \tau \alpha \mu о \tilde{v} \pi \alpha \rho \varepsilon \sigma v ́ \rho \eta)$. A última frase está reservada para a moral que afirma que o que foi contado ( $\delta \lambda o ́$ jos) é oportuno

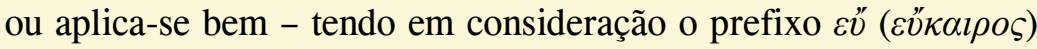

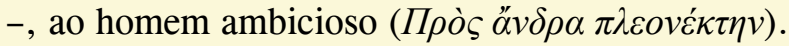

$\mathrm{Na}$ versão latina de Fedro, lemos:

\section{Canis per fluvium carnem ferens}

Amittit merito proprium qui alienum adpetit.

Canis per flumen carnem cum ferret natans,

Lympharum in speculo vidit simulacrum suum,

Aliamque praedam ab altero ferri putans

Eripere voluit; verum decepta aviditas

Et quem tenebat ore dimisit cibum,

Nec quem petebat potuit adeo adtingere. ${ }^{18}$

\footnotetext{
${ }^{18}$ PHAEDRUS. Fabulae Aesopiae. L. Mueller. Leipzig. B. G. Teubner. 1876. Disponível em: http://www.perseus.tufts.edu/hopper/text?doc $=$ Perseus \%3Atext\%3A1999.02.0118\% 3Abook\%3D1\%3Apoem\%3D4. Acesso em 07/08/2016.
} 
Logo no primeiro verso verificamos o conteúdo moral do que será contado. A primeira palavra evidencia a perda gerada pela ambição (Amittit). Assim, perde o que se possui (merito proprium) pelo desejo do que pertence a outro (alienum). Os versos segundo e terceiro são semelhantes ao que se lê em Esopo, um cão (canis $)^{19}$ que enquanto (cum) atravessa a nado (natans) um rio (per flumen) carregando um pedaço de carne (carnem ... ferret) vê no espelho das águas (Lympharum in speculo) o seu simulacro. E pensando ser outra presa (Aliamque praedam) trazida por outro cão ( $a b$ altero ferri) teve vontade de arrancá-la (Eripere voluit). As palavras seguintes conterão a palavra-chave da fábula - aviditas. Traído (Decepta), em verdade (verum), pela sua ambição, o cão perde o pedaço de carne que possuía em sua boca (Et quem tenebat ore dimisit cibum), ficando também sem a presa que de tal modo (adeo) cobiçava (quem petebat).

Analisemos agora a fábula de La Fontaine:

Le chien qui lâche sa proie pour l'ombre

Chacun se trompe ici-bas.

On voit courir après l'ombre

Tant de fous qu'on n'en sait pas

La plupart du temps le nombre.

Au chien dont parle Ésope il faut les renvoyer.

Ce Chien, voyant sa proie en l'eau représentée,

La quitta pour l'image, et pensa se noyer;

La rivière devint tout d'un coup agitée.

À toute peine il regagna les bords,

Et n'eut ni l'ombre ni le corps. ${ }^{20}$

${ }^{19}$ Em latim a tradução correta é cão, pois a expressão $a b$ altero em latim está no masculino (por outro [cão]).

${ }^{20}$ LA FONTAINE, Jean de. Fables. Paris: Flammarion, 1995, p. 71. 
Já em La Fontaine lemos desde o título uma fusão entre Esopo e Fedro, pois daquele toma emprestada a palavra sombra (ombre, $\sigma \kappa i \alpha ́ s)$, e deste a palavra presa (proie, praeda). Os quatro primeiros versos estão dedicados a uma releitura alegórica do espaço humano, caracterizado pelos erros (se trompe) dos habitantes daqui debaixo (ici-bas). Em seguida, mostra-se qual a causa desses erros: tantos doidos (Tant de fous) correm atrás da sombra que não se sabe na maioria das vezes (La plupart du temps) os seus nomes. A homenagem a Esopo aparece no quinto verso, quando La Fontaine afirma que os doidos devem ser remetidos à fábula do cachorro (il faut les renvoyer). É curioso, todavia, que La Fontaine traduza por Chien e não por Chienne, uma vez que ele mesmo nos convida a ler Esopo. Entretanto, a diferença em relação a Esopo e Fedro reside no fato de que o cão toma a imagem de sua presa, refletida na água, pela presa mesma, largando o pedaço que mantinha entre os dentes (la quitta) achando que ela está afundando (se noyer). Devido aos seus movimentos, as águas se agitam (la rivière devint tout d'un coup agitée), e o final já nos é conhecido, o cão fica sem nada (ni l'ombre ni le corps). Chama a atenção a riqueza de detalhes presentes na fábula de La Fontaine, quando comparada com as anteriores: o movimento das águas e a dificuldade com que o cão chega à margem intensificam a sensação da perda.

Por último, destacamos a fábula em que uma raposa se depara com uma máscara de teatro:

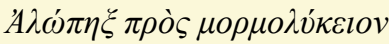

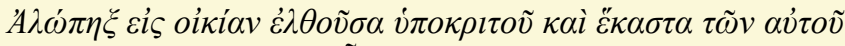

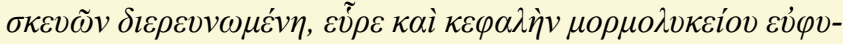

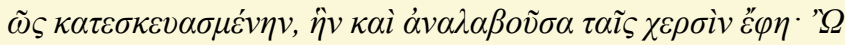

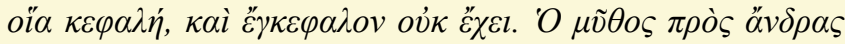

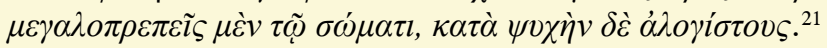

${ }^{21}$ ÉSOPE (Texte établi et traduit par Émile Chambry, 1927). Fables. Paris: Les Belles Lettres, 1967, p.22. 
Certa raposa caminhava em direção à casa de um ator de teatro

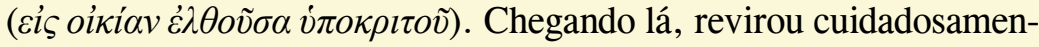

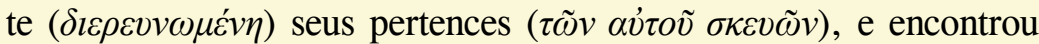
( $\varepsilon \tilde{v} \rho \varepsilon)$ uma máscara trabalhada de forma muito bela ( $\varepsilon \dot{v} \varphi v \tilde{\omega} \varsigma)$. Tomando-a entre as suas patas ( $\tau \alpha \tilde{l} \varsigma \chi \varepsilon \rho \sigma i v)$, disse (है $\varphi \eta)$ : "Oh, que bela

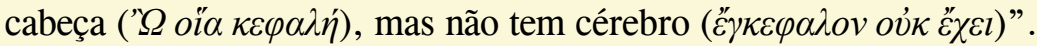
Aqui reside o cerne da fábula, uma vez que o jogo entre as palavras

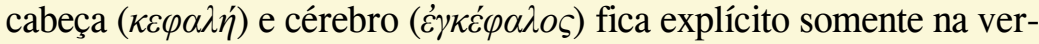
são em grego, mostrando a relação entre uma pura forma exterior e o conteúdo que lhe dá vida. Esta analogia é colocada em evidência nas palavras dedicadas ao tom moral, em que se faz uma diferenciação entre o corpo $(\sigma \tilde{\omega} \mu \alpha)$ e a alma ( $\left.\psi v \chi \eta^{\prime}\right)$, e a fábula, aqui designada pela palavra $\mu \tilde{v} \theta o \varsigma$, seria conveniente para os homens que são magníficos

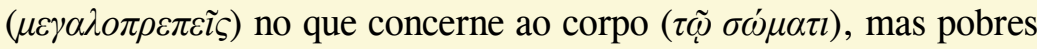

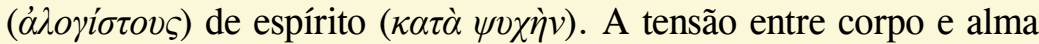
também pode ser visualizada pelas partículas " $\mu \dot{\varepsilon} v \ldots \delta \hat{\varepsilon}$ ", que significam "por um lado... por outro...)".

Quanto à versão latina, vemos que ela é extremamente sintética:

Vulpis ad personam tragicam

Personam tragicam forte vulpis viderat:

O quanta species, inquit, cerebrum non habet!

Hoc illis dictum est, quibus honorem et gloriam

Fortuna tribuit, sensum communem abstulit. ${ }^{22}$

A marcação temporal "certa vez", que antes em grego não aparecia, insere-se aqui (forte). E já no segundo verso encontramos o vocativo - introduzido pelo ' $\Omega$ em Esopo e agora pelo $O$ em Fedro. Como comentávamos antes, o jogo de palavras não

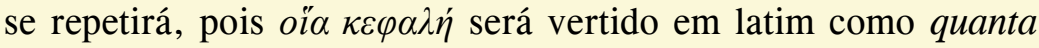

${ }^{22}$ PHAEDRUS. Fabulae Aesopiae. L. Mueller. Leipzig. B. G. Teubner. 1876. Disponível em: http://www.perseus.tufts.edu/hopper/text?doc $=$ Perseus \%3Atext\%3A1999.02.0118\% 3Abook\%3D1\%3Apoem\%3D7. Acesso em 07/08/2016.

Cad. Trad., Florianópolis, v. 38, no 2, p. 97-119, mai-ago, 2018 
species (um exemplar único, belo, que a única palavra grega oï $\alpha$ já dá conta). Fedro não utiliza a palavra caput,-itis para traduzir $\kappa \varepsilon \varphi \alpha \lambda \eta \dot{~}$. A raposa surpreende-se, afirmando que apesar de bela, a máscara não possui cérebro (cerebrum non habet). O conteúdo moral é modificado levemente aqui, pois se afirma que a fábula (Hoc) é dirigida para aqueles (quibus) que a sorte (Fortuna) brindou com honra e glória (honorem et gloriam ... tribuit), mas retirou-lhes (abstulit) a inteligência (sensum communem). O elemento do acaso representado pela palavra Fortuna dá o tom da fábula em Fedro.

Em francês, a mesma fábula está extremamente enriquecida, de modo oposto ao que fizera Fedro:

\section{Le renard et le buste}

Les Grands, pour la plupart, sont masques de théâtre;

Leur apparence impose au vulgaire idolâtre.

L'Âne n'en sait juger que par ce qu'il en voit.

Le Renard, au contraire, à fond les examine,

Les tourne de tout sens ; et, quand il s'aperçoit

Que leur fait n'est que bonne mine,

Il leur applique un mot qu'un Buste de héros

Lui fit dire fort à propos.

C'était un Buste creux, et plus grand que nature.

Le Renard, en louant l'effort de la sculpture:

«Belle tête, dit-il, mais de cervelle point.»

Combien de grands Seigneurs sont Bustes en ce point! ${ }^{23}$

Com esta fábula, fica mais evidente o processo de estetização levado a cabo por La Fontaine, que confere à história um grau de complexidade que não existia em Fedro e em Esopo. La Fontaine até mesmo inclui um animal nesta fábula: o asno ( $L$ 'Ane $)$.

$\overline{{ }^{23} \text { LA FONTAINE, Jean de. Fables. Paris: Flammarion, }}$ 1995, p. 43. 
Em contraste com a ingenuidade deste, a inteligência da raposa se sobressai (à fond les examine). Essa fábula é direcionada aos 'grandes homens' (Les Grands, grands Seigneurs), ou seja, aos poderosos, mas não existe qualquer menção ao acaso ou ao destino. Este direcionamento é reiterado por duas menções: a primeira abre o texto, a segunda o conclui. A fábula de Fedro já era dirigida aos homens que o destino premiou com honra e glória, de modo mais discreto e nuances políticas menos demarcadas; em La Fontaine, dentro de um contexto social e político diverso, no qual os grandes homens, a massa ingênua e a classe intelectual são outros, a moralidade da fábula é reinventada. Sobrevive às modificações contextuais, persistindo a sua pertinência, porém deixa uma margem generosa de aplicação e de múltiplos entendimentos. La Fontaine utiliza uma história da Antiguidade para criticar os homens do seu tempo, reatualizando a moralidade e redirecionando-a para um novo contexto histórico.

É notória esta virtude da fábula de poder ser aplicada às mais diversas situações, e esta flexibilidade é uma característica que contribui para a sobrevivência do gênero através dos séculos. Após considerarmos as versões dessas três fábulas em diferentes períodos históricos, cabe pensarmos sobre a relação das fábulas com o tempo, este entendido não apenas no seu sentido cronológico, mas na complexidade de relações que engendra. Para Benjamin, "A história é objeto de uma construção cujo lugar não é o tempo homogêneo e vazio, mas um tempo saturado de 'agoras'." ${ }^{24}$ Cada agora da fábula, ao mesmo tempo em que recupera a tradição do gênero, o reinventa.

A complexidade temporal da fábula se faz ouvir desde o seu surgimento, marcado pela transmissão oral. A obsessão por citar Esopo como pai do gênero, como comentado anteriormente, é um 'agora' que se multiplica e no qual uma tradição anônima de transmissão oral é reinventada e se plasma na materialidade de um

${ }^{24}$ BENJAMIN, Walter. "Sobre o conceito de História". In.: Magia e técnica, arte e política: ensaios sobre literatura e história da cultura. (Obras escolhidas volume I). Tradução de Sérgio Paulo Rouanet. São Paulo: Brasiliense, 1994, pp.222-232, p.229.

Cad. Trad., Florianópolis, v. 38, no 2, p. 97-119, mai-ago, 2018 
nome. A fábula nasce da reinvenção de psicodinâmicas da oralidade $^{25}$, sendo a sua origem difusa e equívoca. Sempre que ela é resgatada, há um gesto de afirmação de uma tradição, porém essa tradição é reinventada. Assim como não existe um tempo homogêneo, também não existe uma tradição homogênea da fábula. $\mathrm{O}$ papel da imaginação de cada um dos fabulistas em relação a essa tradição deve ser levado em conta, e também as relações novas que as fábulas adquirem com o seu contexto.

Márcia Seabra Neves também pontua as diferenças entre a fábula de Esopo, Fedro e La Fontaine, discutindo a maneira pela qual cada um dos autores contribuiu para o gênero ${ }^{26}$. Enquanto em Esopo a linguagem era mais direta, e a função perlocutória prevalecia, em Fedro os recursos estéticos passam a ganhar mais ênfase; tanto na forma em versos escolhida quanto na elaboração de uma sentença moral mais sofisticada:

Com efeito, quanto mais se avança na diacronia do gênero fabulístico, mais flagrante se torna a importância concedida à narrativa em detrimento da moralidade da fábula, que progressivamente vê decrescer o seu tom sentencioso e pedagógico em benefício do travejamento diegético. ${ }^{27}$

Fedro, como vimos, faz uma recontextualização das fábulas de Esopo, por vezes comentando para o seu leitor as questões do seu próprio trabalho e a postura de tradutor que adotou: fiel à sabedoria

\footnotetext{
${ }^{25}$ Cf. ONG, Walter J. Oralidade e cultura escrita: tecnologias da palavra. [Trad. Enid Abreu Dobránsky]. Campinas: Papirus, 1998. Ong mostra que a forma como as comunidades se relacionam com a palavra - escrita, puramente oral ou mista - se reflete em um conjunto de características do pensamento, em um conjunto de psicodinâmicas. A escrita é uma tecnologia que transforma o modo de conhecer do homem, antes centrado na memória. As psicodinâmicas da oralidade inclem a memorização pelo ritmo, o caráter coletivo dos saberes e dos textos, e sua dimensão ritual.

${ }^{26}$ NEVES, Márcia Seabra. "Fábulas na ágora: de Aristóteles a século das luzes". Matraga, Rio de Janeiro, v.20, n.33, jul/dez 2013.

${ }^{27}$ NEVES, Márcia Seabra. "Fábulas na ágora: de Aristóteles a século das luzes”. Matraga, Rio de Janeiro, v.20, n.33, jul/dez 2013, p.146.
} 
do "Velho", porém adicionando o que julgava conveniente "para que a variedade dessas palavras deleite os sentidos" 28 . O esmero na formulação estética irá culminar, entretanto, com La Fontaine, que séculos mais tarde também desejou tornar as fábulas novas e acabou por consagrar definitivamente o gênero. Vimos, por exemplo, na fábula do cão com o pedaço de carne, que La Fontaine introduz a história com quatro versos que tecem um comentário alegórico sobre a vida presente, remetendo à história de Esopo apenas no quinto verso. Desta forma, o autor cria um jogo temporal no qual o leitor é levado primeiramente a pensar no seu próprio tempo e depois aplica a ele a moralidade desentranhada da fábula antiga.

A sinuosidade, a interpretação labiríntica, o modo não direto de enunciar a moralidade são características que revelam o 'agora' no qual La Fontaine escreveu. Sua linguagem tem o traço exuberante do barroco que Deleuze propôs em $A$ dobra ${ }^{29}$, livro no qual o filósofo francês oferece uma leitura das condições epistemológicas que podem ser derivadas da substituição da linearidade objetiva como padrão formal pela complexidade das dobras proliferantes do barroco. Essa forma complicada e ornamental em tudo contrasta com a objetividade sintética, ainda que esteticamente elaborada, levada a cabo por Fedro.

A presença dessas novidades estão tanto na forma escolhida por La Fontaine quanto na apropriação e remodelação dos promítios e epitímios. Estes são, muitas vezes, completamente modificados - ou até mesmo suprimidos quando não foi possível encaixá-los com graça no texto. La Fontaine privilegia a gaieté, sem dispensar o caráter pedagógico dos seus textos. De fato, é este caráter pedagógico que distingue a fábula enquanto gênero, não permitindo que ela se misture com os demais tipos de narrativa breve. A estetização e a relativização da aplicação moral da fábula não implicam a sua destituição. Quando, no século 18, o gênero irá se desenvolver consideravelmente, esse traço persistirá, ainda que em

${ }^{28}$ FIRMINO, Nicolau. Tradução literal das fábulas de Fedro. São Paulo: Livraria Lusitana, 1941, p. 21.

${ }^{29}$ DELEUZE, G. A dobra: Leibniz e o Barroco. Tradução de Luiz B. L. Orandi. Campinas: Papirus, 1991. 
nova feição. Com G.H. Lessing, por exemplo, a função pública e política da fábula será restaurada, trazendo novamente as propostas de Aristóteles à tona. Um possível desdobramento deste trabalho poderia levar em consideração as contribuições de Lessing, verificando como a sua recusa da ornamentação e o seu distanciamento do modo de narrar de La Fontaine conformam uma nova materialidade linguística para as antigas histórias de Esopo. A irrupção do Romantismo fará com que a fábula acabe sendo relegada a segundo plano. Também o cientificismo do século 19 irá contribuir para o obscurecimento do gênero. Ainda assim, é possível sondar a formulação de um contexto que possa trazer novamente à circulação a antiga fabulística, sem os ranços de uma educação opressora e excessivamente racionalizante, mas no contexto de uma novo processo de aprendizado no qual os animais possam figurar novamente como personagens e exemplos de práticas humanas.

A relação do homem com os animais, mais especificamente a tendência a antropomorfizar gestos e reações dos bichos, tem aparecido nas discussões contemporâneas. Prova disso é o artigo de Mario Perniola "Animali quasi saggi, animali quasi pazzi”. O filósofo italiano empreende uma investigação acerca da relação do homem com os animais desde a Antiguidade, mostrando como a postura dos estoicos nos revela traços da percepção contemporânea: "a ideia de animalidade não é independente da ideia de humanidade." ${ }^{30}$ A condição animal é aproximada da dos sábios, fornecendo exemplos, que desde os filósofos cínicos estão presentes e apresentam ao homem uma visão - seja da virtude, seja dada felicidade. Há tanto os animais quase sábios quanto aqueles quase loucos, os animais que são exemplos da 'bela alma' e também os super-animais, formando um conjunto de exemplos dos quais se desentranham importantes conhecimentos éticos para o homem. As considerações de Perniola nos levam a crer que uma renovação da fábula é também possível no mundo contemporâneo.

${ }^{30}$ PERNIOLA, Mario. “Animali quasi saggi, animali quasi pazzi”. Scienza \& Filosofia. Napoli: Universita degli studi de Napoli Federico II, nº ${ }^{0}$, , pp.11-26, junho de 2012, p.12.

Cad. Trad., Florianópolis, v. 38, no 2, p. 97-119, mai-ago, 2018 
A sobrevivência da fábula está profundamente ligada à sua virtude de se renovar em múltiplos 'agoras', os quais, ao resgatá-la, também recriam o seu passado e se constituem em atos de fundação. É impossível ser fiel à fábula, pois ela é um objeto movente, que ao reiterar-se também se inventa. Essa permeabilidade da fábula ao tempo é uma marca que a acompanha desde as suas funções na psicodinâmica da oralidade e que se demonstra nos gestos de recuperação e reatualização recorrentes nos diversos 'agoras' que constituem, à sua maneira, também os atos de origem desse gênero.

A fábula comporta, assim, uma dualidade: pois é através dessas descontinuidades que ela se conserva, chegando até nós como uma das feições mais populares com que a narrativa breve se apresenta. A sobrevivência das historietas de Esopo podem nos indicar tanto a sua transformação no tempo quanto a própria fluidez dos tempos em si, sendo cada termo latino e francês utilizado por Fedro e La Fontaine também um gesto de invenção de cada termo grego presente nas diversas versões dos textos atribuídos a Esopo, os quais renascem através dos textos ulteriores também naquilo que não foi traduzido e que renasce para a percepção contemporânea.

\section{Referências}

ALMEIDA, Napoleão Mendes de. Gramática Latina: curso único e completo. São Paulo: Saraiva, 2011.

ARISTOPHANES. Aristophanes Comoediae, ed. F.W. Hall and W.M. Geldart, vol. 2. F.W. Hall and W.M. Geldart. Oxford: Clarendon Press, 1907.

ARISTOTLE. Ars Rhetorica. Translated by W. D. Ross. Oxford. Clarendon Press. 1959. 
BAILLY, A. Dictionnaire Grec-Français. Paris: Librairie Hachette, 1950.

BENJAMIN, Walter. "Sobre o conceito de História". In.: Magia e técnica, arte e política: ensaios sobre literatura e história da cultura. (Obras escolhidas volume I). Tradução de Sérgio Paulo Rouanet. São Paulo: Brasiliense, 1994, pp. 222-232.

CECCARELLI, Lucio. Prosodia y métrica del Latín Clásico. Con una introducción a la métrica griega. Traducción de Rocío Carande. Sevilla: Universidad de Sevilla, 1999.

ÉSOPE (Texte établi et traduit par Émile Chambry, 1927). Fables. Paris: Les Belles Lettres, 1967.

FILÓSOFOS PRESOCRÁTICOS. Fragmentos II. Traducción de Ramón Cornavaca. Buenos Aires: Losada, 2009.

FIRMINO, Nicolau. Tradução literal das fábulas de Fedro. São Paulo: Livraria Lusitana, 1941.

GAFFIOT, Félix. Dictionnaire Illustré Latin-Français. Paris: Librairie Hachette, 1934.

HERODOTUS. The Histories - with an English translation by A. D. Godley. Cambridge: Harvard University Press. 1920.

LA FONTAINE, Jean de. Fables. Paris: Flammarion, 1995.

NEVES, Márcia Seabra. "Fábulas na ágora: De Aristóteles ao século das Luzes". Matraga. Rio de Janeiro, v. 20, nº33 jul./dez. 2013, 137-158.

ONG, Walter J. Oralidade e cultura escrita: tecnologias da palavra. Trad. Enid Abreu Dobránsky. Campinas: Papirus, 1998.

PERNIOLA, Mario. "Animali quasi saggi, animali quasi pazzi”. Scienza \& Filosofia. Napoli: Università degli studi di Napoli Federico II, nº 7 , pp.11-26, junho de 2012. 
PHAEDRI (Augusti Liberti). Fabulae Aesopiae. Con note italiane del Prof. Francesco Cantarella. Roma: Casa Editrice Dante Alighieri, 1928.

PHAEDRUS. Fabulae Aesopiae. Ed. L. Mueller. Leipzig: B. G. Teubner, 1876.

PLATÃO. Fédon. Porto Alegre: Globo, 1955.

\section{Site consultado:}

http://www.perseus.tufts.edu/hopper/text?doc $=$ Perseus \%3Atext\%3A1999.02.0118 (consulta às fábulas de Fedro em latim, edição de Lucian Müller).

Recebido em: 02 de novembro de 2017

Aceito em: 08 de fevereiro de 2018 Publicado em: maio de 2018

Juan Manuel Terenzi. E-mail: jmterenzi@hotmail.com

Telma Scherer. E-mail: rumordacasa@gmail.com 